\title{
APLIKASI LOCATION BASED SERVICE PENCARIAN TEMPAT WISATA DAN HOTEL PADA WILAYAH KABUPATEN TIMOR TENGAH UTARA BERBASIS ANDROID
}

\author{
Roland Marvelous Abi, Sentot Achmadi, F. X. Ariwibisono \\ Program Studi Teknik Informatika S1, Fakultas Teknologi Industri \\ Institut Teknologi Nasional Malang, Jalan Raya Karanglo km 2 Malang, Indonesia \\ rolandabi92@gmail.com
}

\begin{abstract}
ABSTRAK
Aplikasi Location Based Service (LBS) banyak dikembangkan karena mempunyai pemanfaatan yang sangat penting untuk berbagai hal, salah satunya untuk informasi pariwisata. Pengembangan pariwisata di kabupaten Timor Tengah Utara (Kab. TTU) sangat minim akan informasi dan akses menuju lokasi wisata yang belum diketahui. Selama ini, wisatawan dapat bertanya pada orang lain maupun browsing di internet. Hal ini menjadi kendala jika terdapat banyak rute yang harus dilewati karena akan menyusahkan atau menghambat wisatawan jika terdapat informasi yang salah atau keliru.

Pembuatan aplikasi pencarian lokasi wisata dan hotel pada Kabupaten Timor Tengah Utara menggunakan Android Studio versi 3.6.2 dan MySQL untuk menyimpan database. Aplikasi ini menerapkan metode location based service untuk mempermudah pengguna dalam menemukan lokasi perangkat penguna dan rute perjalanan menuju lokasi wisata atau hotel yang dipilih. Data yang digunakan pada aplikasi ini yaitu 7 wisata alam, 3 wisata buatan, 4 wisata budaya, 2 wisata religi, 12 hotel dan 10 restoran atau rumah makan.

Dari hasil implementasi dan pengujian yang telah dilakukan aplikasi location based service pencarian tempat wisata dan hotel pada wilayah Kabupaten Timor Tengah Utara berbasis android pada 3 sistem operasi yang berbeda yaitu Pie, Oreo dan Marshmellow didapat kesimpulan fungsi location based service berjalan dengan baik. Pada pengujian pengujian kepuasan pengguna diambil hasil bahwa dari 19 reponden yang telah diberi kuisioner memberikan nilai kepuasan dari segi penggunaan, tampilan antarmuka, manfaat aplikasi dengan presentase sebanyak $0 \%$ pengguna menyatakan sangat tidak setuju, $0 \%$ pengguna menyatakan tidak setuju, 12.8\% menyatakan bahwa pengguna netral, $58.6 \%$ menyatakan bahwa pengguna Setuju dan $28.5 \%$ menyatakan bahwa pengguna sangat setuju.
\end{abstract}

Kata Kunci : Android, LBS, Wisata, Hotel

\section{PENDAHULUAN}

Salah satu sektor yang berperan penting dan dianggap menguntungkan untuk dikembangkan adalah pariwisata. Kekayaan pariwisata dapat digunakan sebagai sumber yang sangat menghasilkan dan dapat dikembangkan sebagai salah satu aset bagi bangsa dan negara.

Kekayaan potensi pariwisata tidak hanya dimiliki daerah-daerah tertentu melainkan salah satu kabupaten yang letaknya di sebelah Utara pulau Timor Provinsi Nusa Tenggara Timur, yakni Kabupaten Timor Tengah Utara juga memiliki potensi dan daya tarik wisata yang unik dan menarik. Pengembangan pariwisata di kabupaten Timor Tengah Utara atau yang biasa disebut kabupaten TTU masih dikatakan sangat minim dan akses menuju lokasi pariwisata sering terkendala oleh lokasi yang belum diketahui dan jalur perjalanan yang ingin dilewati. Selama ini, jika ingin mengunjungi tempat pariwisata yang ada di kabupaten TTU, seorang calon wisatawan dapat bertanya pada orang lain maupun browsing di internet. Hal ini kadang menjadi kendala jika terdapat banyak rute yang harus dilewati karena akan menyusahkan atau menghambat wisatawan jika terdapat informasi yang salah atau keliru.
Oleh karena itu penulis bermaksud membuat aplikasi mobile dengan menggunakan konsep/metode Location Based Service (LBS) di platform android. Location based services adalah layanan berbasis lokasi atau istilah umum yang sering digunakan untuk menggambarkan teknologi yang digunakan untuk menemukan lokasi perangkat yang pengguna gunakan. Layanan ini menggunakan teknologi global positioning service (GPS) dan cell-based location dari Google. Dengan layanan GPS pada aplikasi ini akan mempermudah wisatawan mencari lokasi dan mampu menampilkan lokasi yang dipilih dan juga informasi peta maupun rute perjalanan menuju ke lokasi wisata alam dan hotel yang ada di wilayah kabupaten Timor Tengah Utara.

\section{TINJAUAN PUSTAKA}

\subsection{Penelitian Terdahulu}

Penelitian yang dilakukan oleh Jaya Prasetyo Adi, 2018, Pencarian Hotel Terdekat Di Kota Malang Mengunakan Metode Location Based Service. Pada penelitian ini menggunakan dua unsur utama metode Location Based Service (LBS) yaitu Location Manager (API Maps) yang digunakan untuk menampilkan, memanipulasi peta serta Location Providers (API Location) yang digunakan untuk 
pencarian lokasi. Aplikasi ini menggunakan system operasi android yang digunakan untuk memudahkan pengguna android untuk mencari aplikasi pencarian hotel terdekat di kota Malang agar wisatawan dari luar kota ingin mencari hotel di Kota Malang lebih mudah dan cepat untuk mencari hotel terdekat.[1]

Penelitian yang dilakukan oleh Khaidir Ali, 2017, Aplikasi Pencarian Tempat Ibadah Menggunakan Metode Lbs (Location Based Service) Berbasis Android. Pada penelitian ini menghasilkan sebuah aplikasi yang didalamnya terdapat informasi tentang tempat Ibadah (Masjid, Gereja, klenteng, vihara) berupa lokasi yang disajikan dalam bentuk peta dengan menggunakan Google Maps API (Aplication Programming Interface), selain itu pengguna juga bisa menampilkan jalan (direction) dari tempat pengguna berada menuju lokasi layanan tempat ibadah. Aplikasi ini dapat memberikan informasi tentang lokasi tempat ibadah. Melalui Google Maps API dan dapat menampilkan jadwal berbasis lokasi.[2]

Penelitian yang dilakukan oleh Ariyani Fitriana, 2018, Aplikasi Pencarian Lokasi Lembaga Kursus Dan Pelatihan Di Kota Malang Menggunakan Metode Lbs (Location Based Service). Pada penelitian ini dibuat suatu sistem yang dapat mencari lokasi lembaga kursus dan pelatihan di kota Malang untuk pengguna smartphone Android dengan menerapkan metode Location Based Service (LBS) untuk melakukan pencarian lokasi.[3]

Penelitian yang dilakukan oleh Salman Alfarisi Hasbullah, 2017, Aplikasi Pencari Tempat Pencucian Mobil Dan Motor Di Kota Malang Menggunakan Metode Location Based Service (Lbs) Berbasis Android. Pemanfaatan teknologi smartphone dan Location Based Service pada penelitian ini menghasilkan sebuah aplikasi yang dapat membantu pengendara kendaraan bermotor yang ingin mencuci kendaraan mereka tapi kesulitan untuk mencari tempat-tempat pencucian mobil dan motor yang ada di Kota Malang. Sistem yang akan dibangun merupakan implementasi Location Based Sevice yang bertujuan untuk menemukan dan mengarahkan pengguna kepada tempat pencucian mobil dan motor di Kota Malang.[4]

Penelitian yang dilakukan oleh Ariefka Rahman, 2018, Aplikasi Mad Ento "Madura Explore And Tour" Dengan Penerapan Metode Location Based Service (Lbs) Berbasis Android. Pada penelitian ini dibuat aplikasi yang menggunakan system operasi android yang bertujuan untuk memudahkan pengguna yang dalam hal ini sasarannya ialah wisatawan, untuk dapat mempermudah perjalan wisatanya di Pulau Madura. Aplikasi Mad Ento memfasilitasi wisatawan akan informasi tempat wisata, pusat oleh-oleh, penginapan, kuliner dan event. Aplikasi ini dilengkapi dengan metode Location Based Service (LBS) yang mana metode tersebut memanfaatkan fasilitas Google yaitu Google Maps yang mana telah tersedia Aplication Program Interface (API) untuk memungkinkan pengunanya untuk melakukan overlay dengan data tertentu pada peta misalnya menampilkan posisi dengan menggambarkan sebuah penanda. [5]

\subsection{Dasar Teori}

\subsubsection{Location Based Services (LBS)}

Layanan Berbasis Lokasi atau lebih dikenal dengan Location Based Service (LBS) adalah layanan informasi yang dapat diakses melalui mobile device dengan menggunakan mobile network, yang juga dilengkapi kemampuan untuk memanfaatkan lokasi pada mobile device tersebut. Terdapat dua unsur utama pada Location Based Service yaitu:

a. Location Manager (API Maps) menyediakan tools/source untuk Location Based Service, Application Programming Interface (API) Maps menyediakan fasilitas untuk menampilkan, memanipulasi maps/peta beserta feature feature lainnya seperti tampilan satelit, street (jalan), maupun gabungannya. Paket ini berada pada com.google.adroid.maps.

b. Location Provider (API Location) menyediakkan teknologi pencarian lokasi yang digunakan oleh device/perangkat. API Location berhubungan dengan data GPS (Global Positioning System) dan data lokasi real-time. API Location berada pada paket android yaitu dalam paket android.location. Location Manager dapat menentukan lokasi kita saat ini, track gerakan/perpindahan, serta kedekatan dengan lokasi tertentu dengan mendeteksi perpindahan.[6]

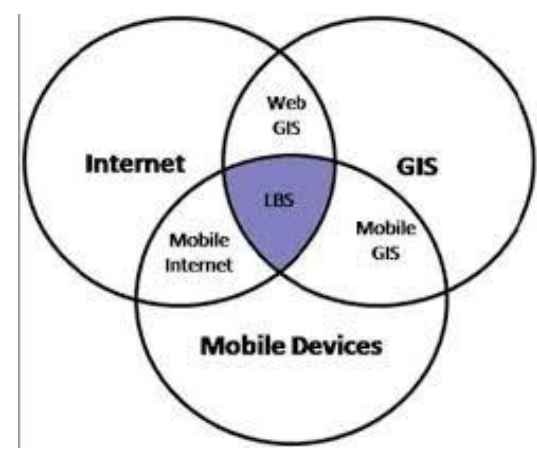

Gambar 2.1 Teknologi Location Based Service (Edi Budiman, 2016)

\subsubsection{Java}

Java merupakan suatu bahasa pemrograman, dan sekaligus suatu platform di dunia software komputer. Java dikenal sebagai suatu bahasa pemrograman tingkat tinggi. Java mudah dipelajari, terutama bagi programmer yang telah mengenal $\mathrm{C} / \mathrm{C}++$. Bahasa pemrograman java berorientasi objek yang merupakan paradigma pemrograman masa depan. Java dirancang menjadi handal dan aman sebagai suatu bahasa pemograman.

Java dibuat agar dapat dijalankan di semua platform. Dan juga untuk menghasilkan aplikasi - 
aplikasi dengan performansi yang terbaik, seperti aplikasi database Oracle $8 \mathrm{i} / 9 \mathrm{i}$ yang core-nya dibangun menggunakan bahasa pemrograman Java. Java bersifat neutral architecture, karena Java Compiler yang digunakan untuk mengkompilasi kode program Java dirancang untuk menghasilkan kode yang netral terhadap semua arsitektur perangkat keras yang disebut sebagai Java Bytecode.[7]

\subsubsection{MySQL}

MySQL adalah sebuah perangkat lunak sistem manajemen basis data SQL. MySQL adalah Relational Database Management System (RDBMS) yang didistribusikan secara gratis dibawah lisensi General Public Licence (GPL). Oleh karena itu setiap orang bebas untuk menggunakan MySQL, namun tidak boleh dijadikan produk turunan yang bersifat komersial.

MySQL sebenarnya merupakan turunan salah satu konsep utama dalam database sejak lama, yaitu SQL (Structured Query Language). SQL adalah sebuah konsep pengoperasian database, terutama untuk pemilihan atau seleksi dan pemasukan data, yang memungkinkan pengoperasian data dikerjakan dengan mudah secara otomatis. Keandalan suatu sistem database (DBMS) dapat diketahui dari cara kerja optimizer-nya dalam melakukan proses perintah-perintah SQL, yang dibuat oleh user maupun program-program aplikasinya. Sebagai database server,

MySQL dapat dikatakan lebih unggul dibandingkan database server lainnya dalam query data. Hal ini terbukti untuk query yang dilakukan oleh single user, kecepatan query MySQL bisa sepuluh kali lebih cepat dari PostgreSQL dan lima kali lebih cepat dibandingkan Interbase.[8]

\subsubsection{Android Studio}

Android studio adalah IDE (Integrated Development Environment) resmi untuk pengembangan aplikasi Android dan bersifatopen sourceatau gratis. Sejak peluncuran Android Studio ini diumumkan oleh Google pada 16 mei 2013 pada event Google I/O Conference untuk tahun 2013., Android Studio mengantikan Eclipse sebagai IDE resmi untuk mengembangkan aplikasi. Android, Android studio sendiri dikembangkan berdasarkan IntelliJ IDEA yang mirip dengan Eclipse disertai dengan ADT plugin (Android Development Tools). Fitur yang dimiliki Android studio yaitu :

1. Projek berbasis padaGradle Build.

2. Refactory dan pembenahan bug yang cepat.

3. Toolsbaru yang bernama "Lint" diklaim dapat memonitor kecepatan, kegunaan, serta kompetibelitas aplikasi dengancepat.

4. Mendukung Proguard And App-signing untuk keamanan.

5. Memiliki GUI aplikasi android lebih mudah.

6. Didukung oleh Google Cloud Platfrom untuk setiap aplikasi yang dikembangkan.[9]

\subsubsection{Java Script Object Nonation (JSON)}

JSON (JavaScript Object Notation) adalah format pertukaran data yang ringan, mudah dibaca dan ditulis oleh manusia, serta mudah diterjemahkan dan dibuat (generate) oleh komputer. Format JSON dibuat berdasarkan bagian dari Bahasa Pemprograman Java Script, Standar ECMA-262 Edisi ke-3 - Desember 1999. JSON merupakan format teks yang tidak bergantung pada bahasa pemprograman apapun karena menggunakan gaya bahasa yang umum digunakan oleh programmer. Oleh karena itu, JSON menjadi ideal sebagai bahasa pertukaran-data.

Dua struktur JSON yaitu:

1. Kumpulan pasangan nama/nilai. Pada beberapa bahasa, hal ini dinyatakan sebagai objek (object), rekaman (record), struktur (struct), kamus (dictionary), tabel hash (hash table), daftar berkunci (keyed list), atau associative array.

2. Daftar nilai terurutkan (an ordered list of values). Pada kebanyakan bahasa, hal ini dinyatakan sebagai larik (array), vektor (vector), daftar (list), atau urutan (sequence).[9]

\subsubsection{Google Maps API}

Google maps adalah layanan dari google yang mempermudah pengunanya untuk melakukan kemampuan pemetaan untuk aplikasi yang dibuat. Google maps API memungkinkan pengembangan untuk mengintegrasikan Google Maps ke dalam situs web. Penggunaan Google Maps Api memungkinkan untuk menanamkan situs Google Maps ke dalam situs eksternal, di mana situs data tertentu dapat dilakukan overlay..[9]

\section{METODE PENELITIAN}

\subsection{Perancangan Sistem}

Sistem yang akan dibangun pada penelitian ini yaitu implementasi Location Based Services pada perangkat android dimana pengguna dapat mencari dan menemukan lokasi wisata serta hotel yang ada di dalam aplikasi yang akan dikembangkan.

\subsection{Blok Diagram Sistem}

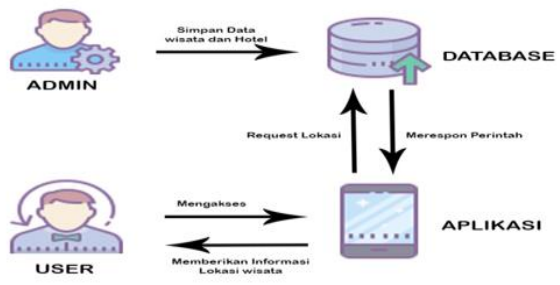

Gambar 3.2 Blok diagram system

Pada diagram blok sistem menjelaskan bahwa admin bertugas untuk menginput data berupa informasi wisata dan hotel dan juga titik koordinat lokasi wisata atau hotel ke dalam database agar bisa diakses user dari aplikasi android. 


\subsection{Flowchart Sistem}

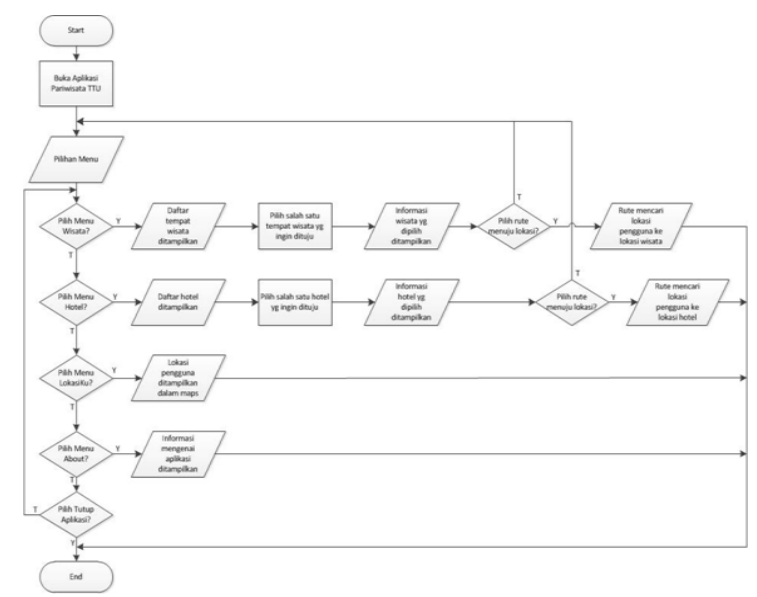

Gambar 3.3 Flowchart Sistem

Pada gambar 3.3 ditampilkan flowchart dari sistem/aplikasi yang akan dikembangkan. Dimana aplikasi dimulai dari start lalu membuka aplikasi pencarian lokasi tempat wisata dan akan ditampilkan menu utama. Menu utama ada 4, yaitu :

1. Jika kita memilih menu Daftar wisata, maka sistem akan menampilkan daftar tempat wisata yang ada di kabupaten Timor Tengah Utara, kemudian kita memilih salah satu dari wisata yang ada. Setelah memilih maka akan ditampilkan data/informasi mengenai wisata tersebut. Jika kita memilih untuk melihat rute/petunjuk jalan ke lokasi tersebut, klik tombol "rute" maka sistem akan menampilkan lokasi pengguna sekaligus rute menuju lokasi tempat wisata tersebut

2. Jika memilih menu Daftar hotel, maka sistem akan menampilkan daftar hotel yang ada di kabupaten Timor Tengah Utara, kemudian kita memilih salah satu dari hotel yang ada. Setelah memilih maka akan ditampilkan data/informasi mengenai hotel tersebut. Jika kita memilih untuk melihat rute/petunjuk jalan ke lokasi tersebut, klik tombol "rute" maka sistem akan menampilkan lokasi pengguna sekaligus rute menuju lokasi tempat hotel tersebut.

3. Jika kita memilih menuLokasiku, maka sistem akan menampilkan lokasi pengguna aplikasi saat ini.

4. Jika memilih menu About, maka akan ditampilkan informasi mengenai aplikasi pencarian lokasi tempat wisata di kabupaten Timor Tengah Utara.

5. Jika memilih Tutup Aplikasi maka aplikasi akan dihentikan.

\section{HASIL DAN PEMBAHASAN}

4.1 Implementasi Sistem dan Penjelasan Aplikasi

Implementasi sistem adalah proses menerapkan rancangan sistem yang telah dibuat agar bisa dijalankan pada kenyataannya. Berdasarkan implemetasi sistem ini dapat diketahui sejauh mana keberhasilan dari rancangan yang telah dibuat.

Sebelum menjalankan aplikasi yang telah dibuat, pengguna harus memastikan dalam mengakses aplikasi tersebut harus terhubung ke internet untuk dapat menjalankan Aplikasi Location Based Service Pencarian Tempat Wisata dan Hotel Pada Wilayah Kabupaten Timor Tengah Utara Berbasis Android

\subsection{Tampilan Aplikasi}

\section{Tampilan Menu Utama}

\section{Pariwisata Kab. TTU}

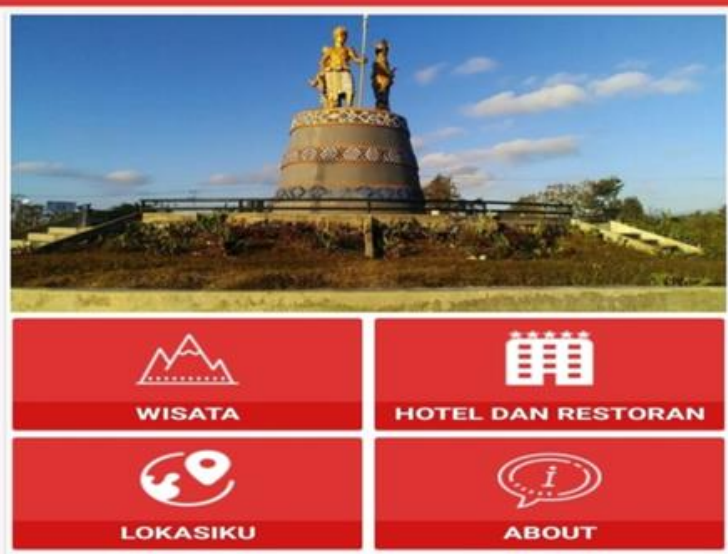

Gambar 4.1 Tampilan Menu Utama.

\section{Tampilan Menu Wisata}

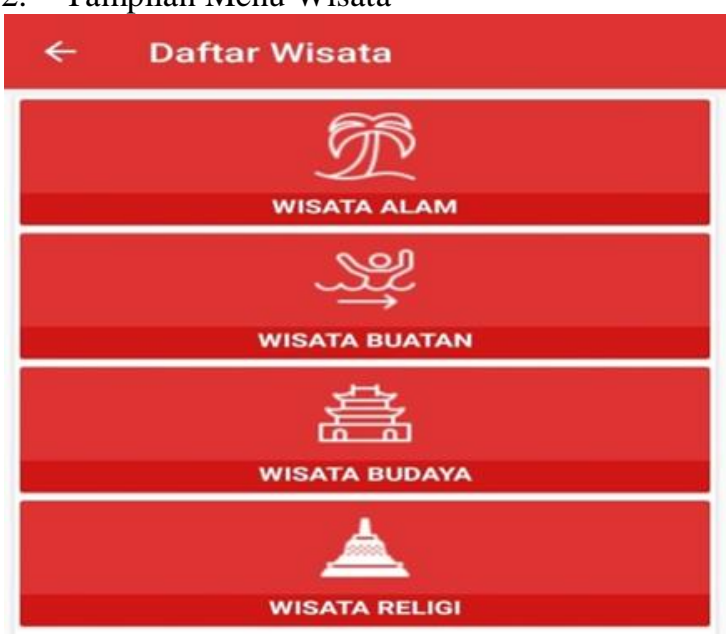

Gambar 4.2 Tampilan Menu Wisata. 
3. Tampilan Menu Wisata Alam

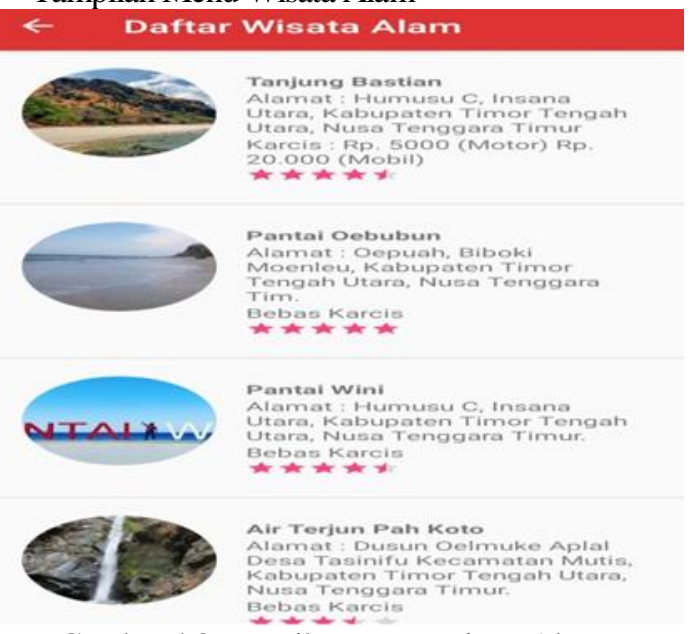

Gambar 4.3 Tampilan Menu Wisata Alam.

4. Tampilan Infomasi Tempat Wisata Alam

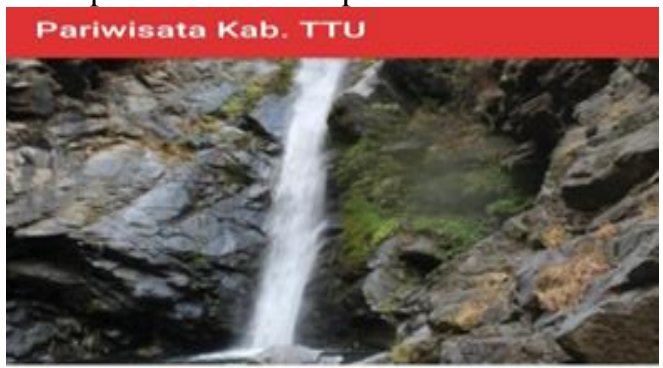

Air Terjun Pah Koto

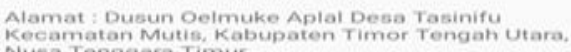

Obyek Wisata ini, terletak di Dusun Oelmuke Aplat Desa

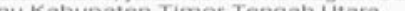
Dalam kawasan ini terdapat beberapa Air Terjun dengen ketinggian yang berbeda-beda. Vang paling tinggi lainnye 5 meter dan 3 meter Sumber Al Teriun in d Gunung Bikekneno. Alam Pegunungan yang indah dan Bebas Karcis

Gambar 4.4 Tampilan Infomasi Tempat Wisata Alam

5. Tampilan Rute Perjalanan Menuju Tempat Wisata Alam

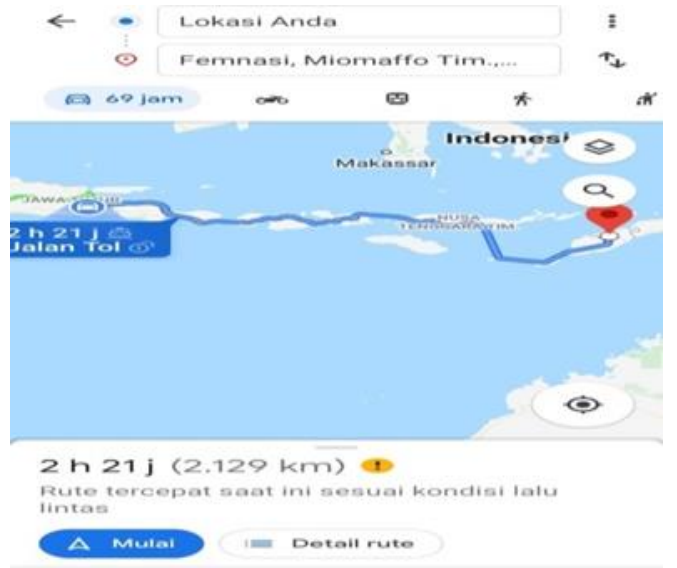

Gambar 4.5 Tampilan rute perjalanan menuju tempat wisata alam
6. Tampilan Menu Wisata Buatan

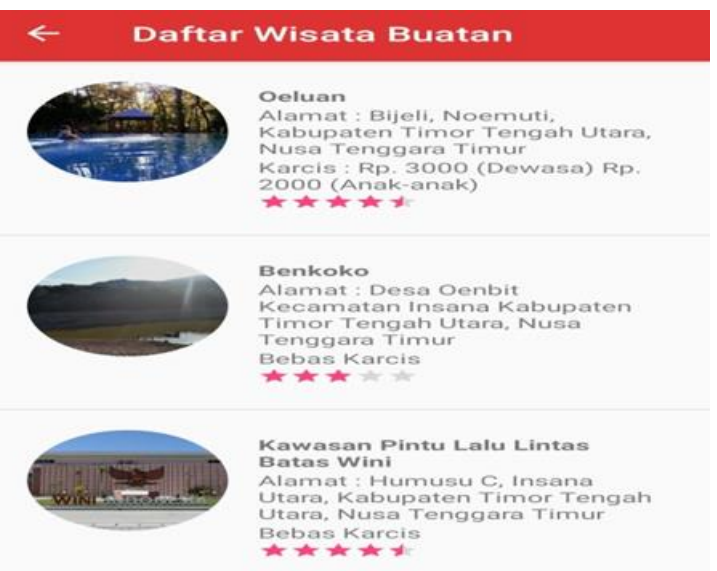

Gambar 4.6 Tampilan menu wisata buatan

7. Tampilan Infomasi Tempat Wisata Buatan

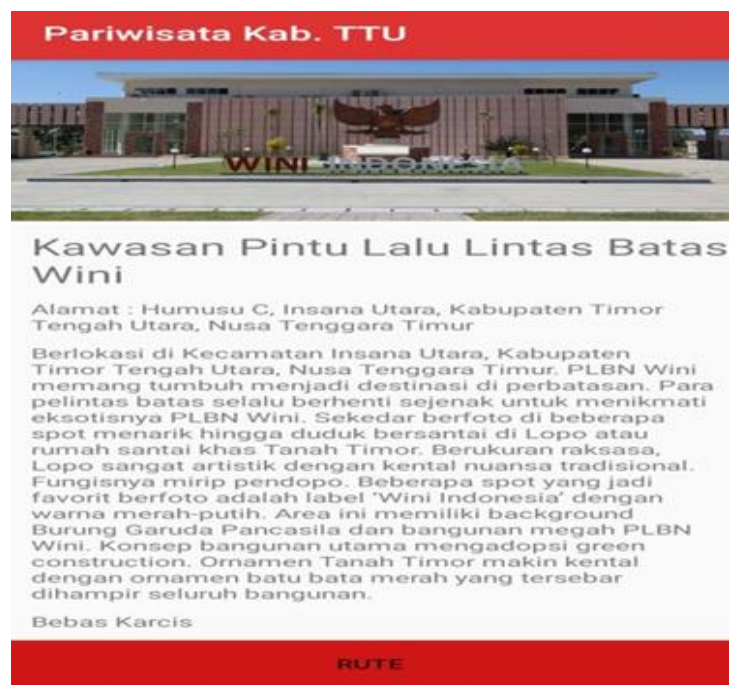

Gambar 4.7 Tampilan informasi tempat wisata buatan

8. Tampilan Rute Perjalanan Menuju Tempat Wisata Buatan

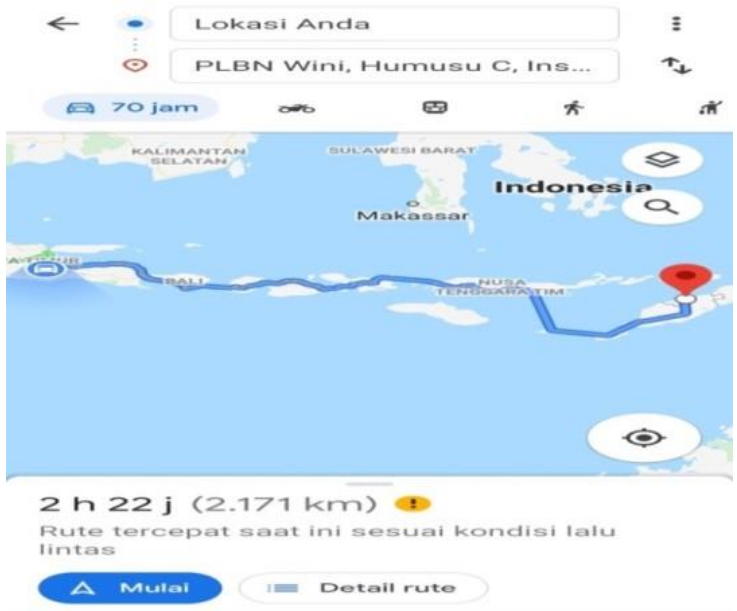

Gambar 4.8 Tampilan rute perjalanan menuju tempat wisata buatan 
9. Tampilan Menu Wisata Budaya

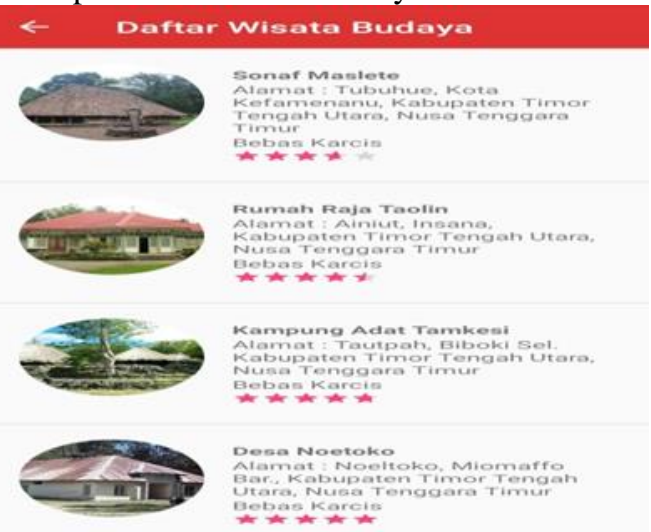

Gambar 4.9 Tampilan menu wisata budaya

10. Tampilan Infomasi Tempat Wisata Budaya Pariwisata Kab. TTU

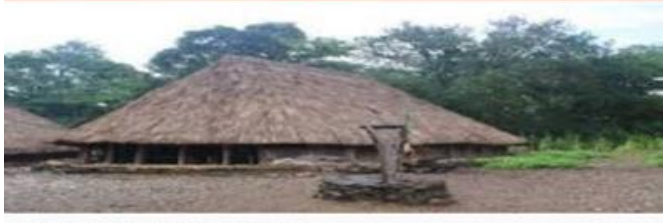

Sonaf Maslete

Alamat Tubuhue, Kota Kefamenanu, Kabupaten Timor

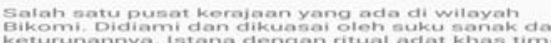

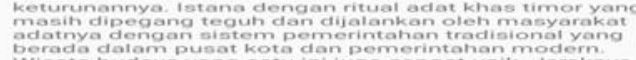

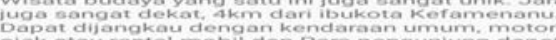

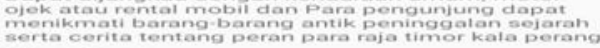

Gambar 4.10 Tampilan informasi tempat wisata budaya

11. Tampilan Rute Perjalanan Menuju Tempat Wisata Budaya

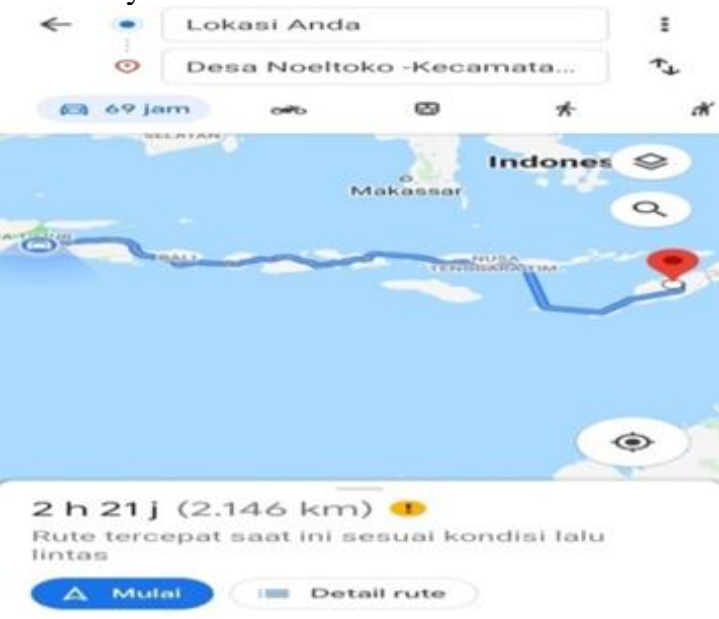

Gambar 4.11 Tampilan rute perjalanan menuju tempat wisata budaya
12. Tampilan Menu Wisata Religi

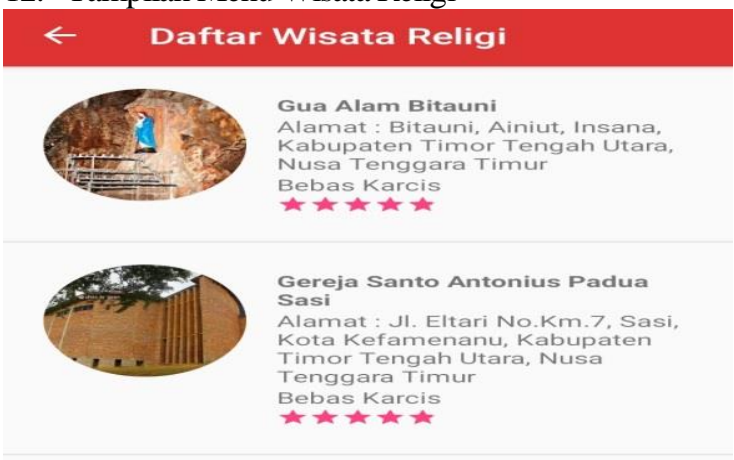

Gambar 4.12 Tampilan menu wisata religi

\section{Tampilan Infomasi Tempat Wisata Religi}

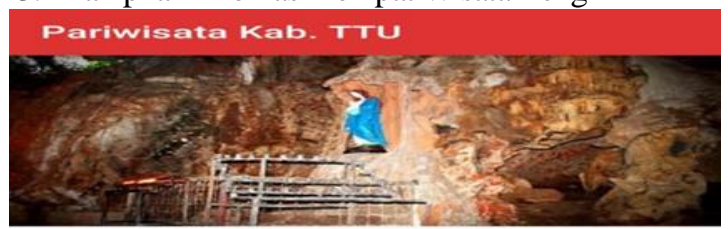

Gua Alam Bitauni

Alamat Bitauni, Ainiut, Insana, Kabu

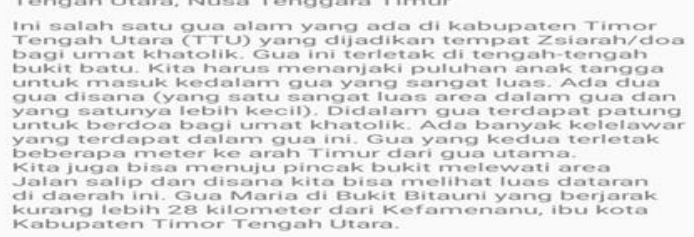

Bebas Karcis

Gambar 4.13 Tampilan informasi tempat wisata religi

14. Tampilan Rute Perjalanan Menuju Tempat Wisata Religi

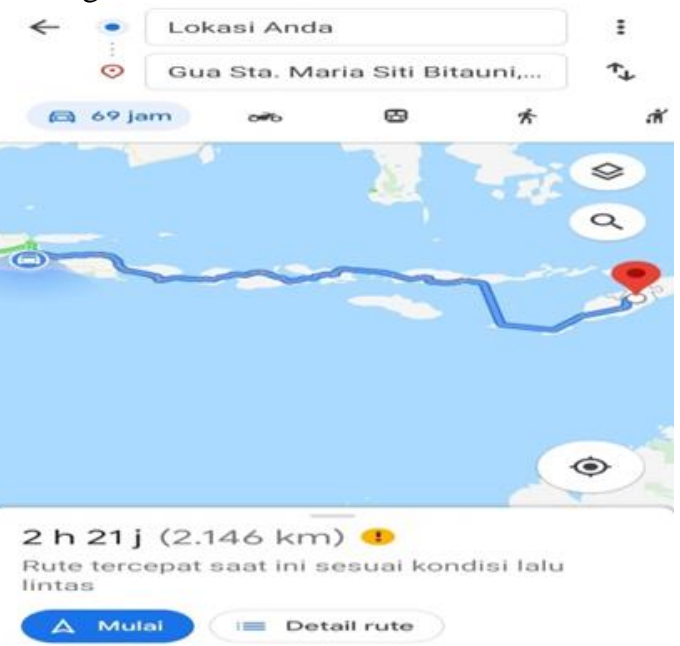

Gambar 4.14 Tampilan rute perjalanan menuju tempat wisata religi 
15. Tampilan Menu Hotel Dan Restoran
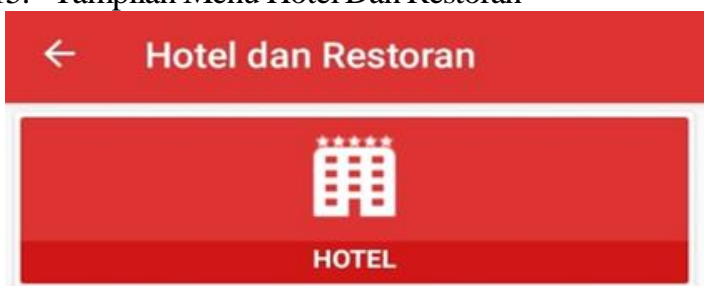

\section{III)}

RESTORAN DAN RUMAH MAKAN

Gambar 4.15 Tampilan Menu Hotel dan Restoran.

16. Tampilan Menu Hotel

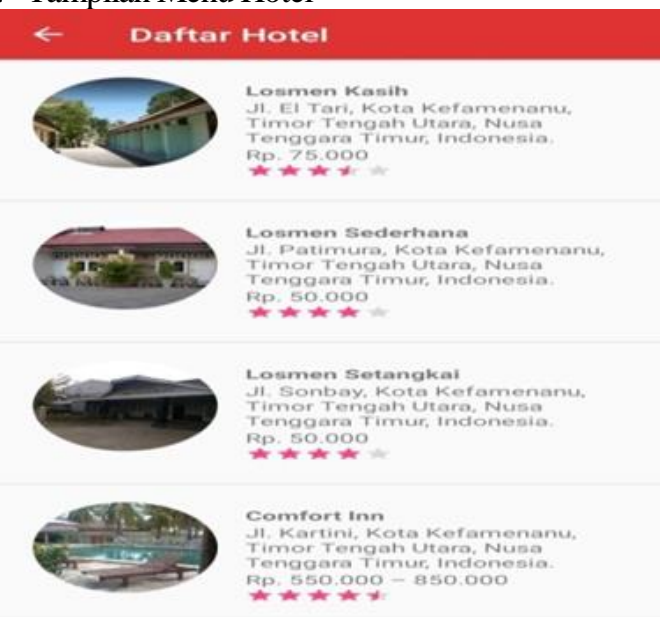

Gambar 4.16 Tampilan menu hotel

17. Tampilan Infomasi Hotel

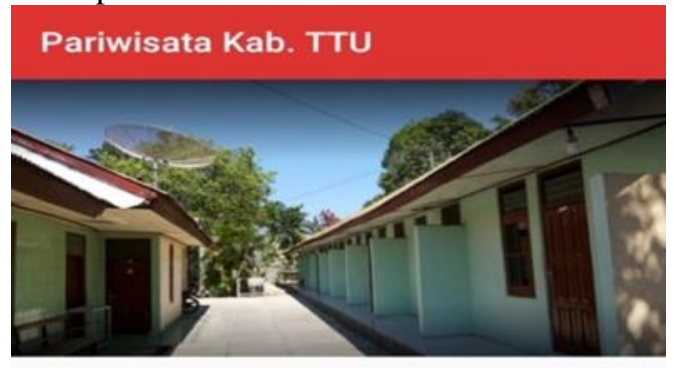

\section{Losmen Kasih}

JI. El Tari, Kota Kefamenanu, Timor Tengah Utara, Nusa Tenggara Timur, Indonesia.

Fasilitas properti

Aktivitas Anak-Anak (Sesuai untuk Anak-Anak/ Keluarga)

Rp. 75.000

\section{RUTE}

Gambar 4.17 Tampilan informasi hotel
18. Tampilan Rute Perjalanan Menuju Hotel

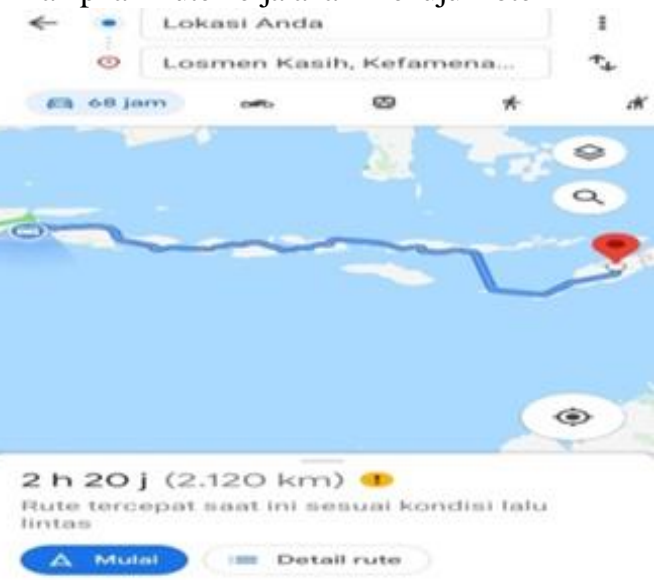

Gambar 4.18 Tampilan rute perjalanan menuju hotel

19. Tampilan Menu Restoran dan Rumah Makan

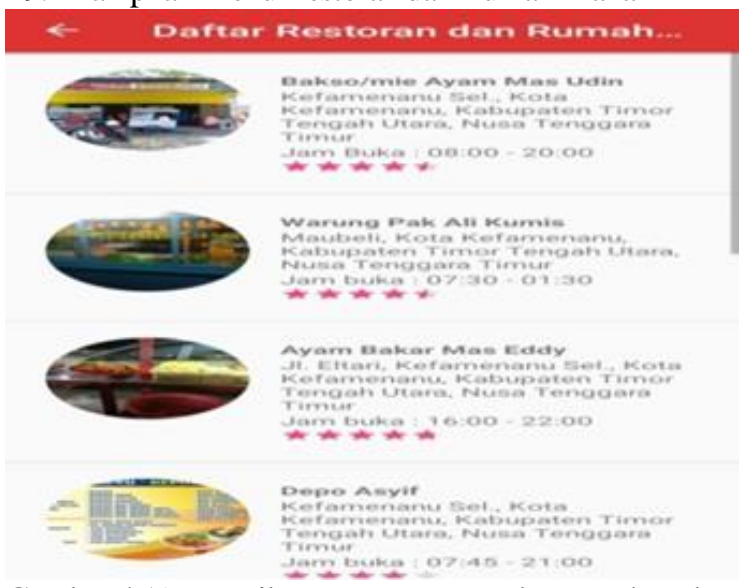

Gambar 4.19 Tampilan menu restoran dan rumah makan

20. Tampilan Infomasi Restoran

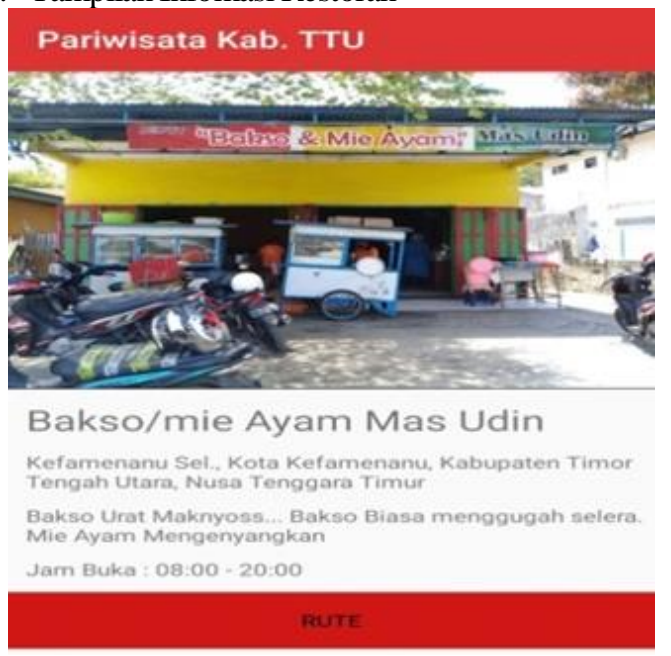

Gambar 4.20 Tampilan informasi restoran 
21. Tampilan Rute Perjalanan Menuju Restoran

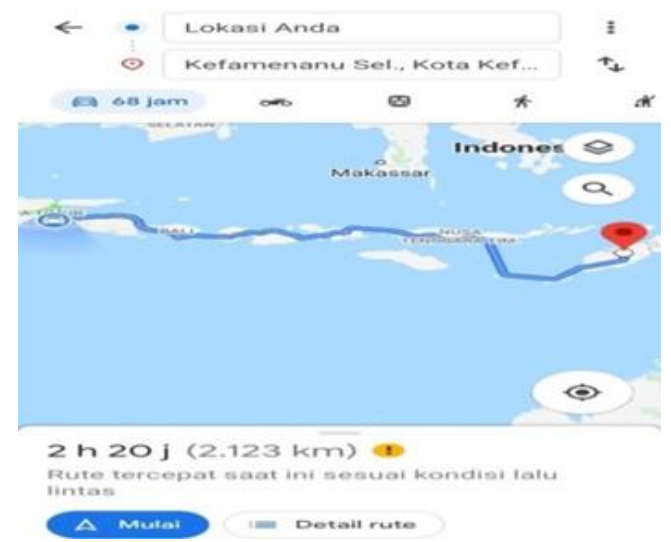

Gambar 4.21 Tampilan rute perjalanan menuju restoran

22. Tampilan Menu LokasiKu

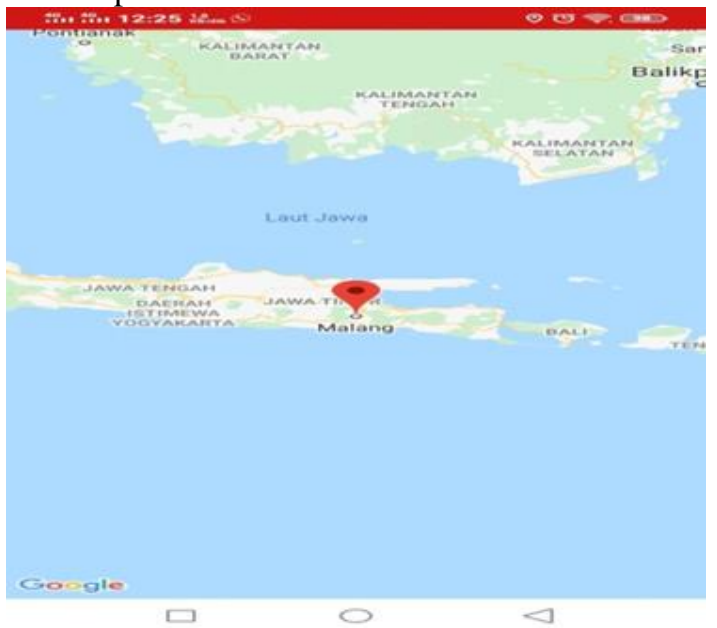

Gambar 4.22 Tampilan Menu LokasiKu.

\section{Tampilan Menu About}

\section{$\leftarrow \quad$ About}

APLIKASI LOCATION BASED SERVICE PENCARIAN TEMPAT WISATA DAN HOTEL PADA WILAYAH KABUPATEN TIMOR TENGAH UTARA BERBASIS ANDROID

INSTITUT TEKNOLOGI NASIONAL MALANG

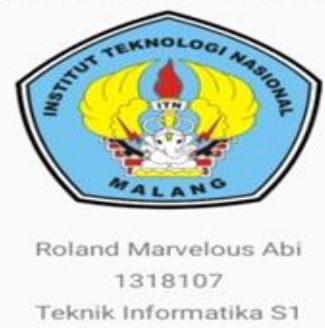

Gambar 4.23 Tampilan Menu About

\subsection{Pengujian Fungsional Sistem}

Pengujian sistem merupakan proses menampilkan sistem dengan maksud untuk menemukan adanya kesalahan atau tidak pada sistem sebelum sistem dipublikasikan untuk digunakan oleh masyarakat. Hasil pengujian sistem ditunjuakkan pada Tabel 4.1 sebagai berikut.

Tabel 4.1 Tabel hasil pengujian fungsional

\begin{tabular}{|c|l|c|c|c|c|}
\hline \multirow{2}{*}{ No. } & \multicolumn{2}{|c|}{ Fungsi } & \multicolumn{4}{c|}{ Android OS } \\
\cline { 3 - 6 } 1 & A & B & C & D \\
\hline & $\begin{array}{l}\text { Menampilkan informasi dari } \\
\text { menu wisata, hotel dan } \\
\text { restoran, lokasiku dan about }\end{array}$ & $\checkmark$ & $\checkmark$ & $\checkmark$ & $\checkmark$ \\
\hline 2 & $\begin{array}{l}\text { Menampilkan lokasi } \\
\text { pengguna pada peta }\end{array}$ & $\checkmark$ & $\checkmark$ & $\checkmark$ & $\checkmark$ \\
\hline \multirow{2}{*}{3} & $\begin{array}{l}\text { Menampilkan daftar Wisata } \\
\text { Alam, Wisata Buatan, } \\
\text { Wisata Budaya, Wisata } \\
\text { Religi dan juga Hotel dan } \\
\text { Restoran }\end{array}$ & $\checkmark$ & $\checkmark$ & $\checkmark$ & $\checkmark$ \\
\hline & $\begin{array}{l}\text { Menampilkan informasi } \\
\text { Wisata Alam, Wisata } \\
\text { Buatan, Wisata Budaya, } \\
\text { Wisata Religi dan juga Hotel } \\
\text { dan Restoran }\end{array}$ & $\checkmark$ & $\checkmark$ & $\checkmark$ & $\checkmark$ \\
\hline 5 & $\begin{array}{l}\text { Menampilkan Penanda dari } \\
\text { lokasi wisata yang di pilih }\end{array}$ & $\checkmark$ & $\checkmark$ & $\checkmark$ & $\checkmark$ \\
\hline 6 & $\begin{array}{l}\text { Menampilkan rute dari } \\
\text { wisata yang di pilih }\end{array}$ & $\checkmark$ & $\checkmark$ & $\checkmark$ & $\checkmark$ \\
\hline
\end{tabular}

Keterangan :

$\sqrt{ }=$ Berjalan

$\mathrm{x}=$ Tidak Berjalan

Keterangan :

Perangkat A:

1. Merk : Vivo Y15

2. Ram : 4 GB

3. Ukuran Layar : 6.35 inches

4. Versi Android: Android 9.0 (Pie)

Perangkat B:

1. Merk : Oppo A5s

2. Ram : 3 GB

3. Ukuran Layar : 6.2 inches

4. Versi Android : Android 8 (Oreo)

Perangkat C:

1. Merk : Samsung Galaxy J5 Prime

2. Ram : 2 GB

3. Ukuran Layar : 5.0 inches

4. Versi Android: Android 6 (Marshmallow)

Perangkat D:

1. Merk : Samsung Galaxy Tab 3

2. Ram : 1 GB

3. Ukuran Layar : 7.0 inches

4. Versi Android : Android 4.4 (KitKat)

\subsection{Pengujian Pengguna}

Untuk mengetahui respon pengguna terhadap aplikasi yang telah dibuat oleh penulis, maka penulis mengajukan 7 pertanyaan kepada 19 orang responden. Pada pengujian kepuasan pengguna diambil hasil bahwa dari 19 reponden yang telah diberi kuisioner memberikan nilai kepuasan dari segi penggunaan, tampilan antarmuka, manfaat aplikasi dengan presentase sebanyak $0 \%$ pengguna menyatakan sangat tidak setuju, $0 \%$ pengguna menyatakan tidak setuju, $12.8 \%$ menyatakan bahwa 
pengguna netral, 58.6\% menyatakan bahwa pengguna Setuju dan $28.5 \%$ menyatakan bahwa pengguna sangat setuju.

Tabel 4.2 Tabel hasil pengujian terhadap pengguna

\begin{tabular}{|r|l|c|c|c|c|c|}
\hline \multirow{2}{*}{$\begin{array}{c}\text { No } \\
\text { 1. Pernyataan }\end{array}$} & \multicolumn{5}{|c|}{ Penilaian } \\
\cline { 2 - 6 } & $\begin{array}{l}\text { Informasi yang disediakan } \\
\text { mudah dimengerti }\end{array}$ & - & - & 1 & 11 & 7 \\
\hline 2. & $\begin{array}{l}\text { Menu atau Fitur mudah } \\
\text { digunakan }\end{array}$ & - & - & 1 & 11 & 7 \\
\hline 3. & Posisi Pengguna sudah akurat & - & - & 3 & 13 & 3 \\
\hline 4. & $\begin{array}{l}\text { Proses menentukan lokasi } \\
\text { cepat }\end{array}$ & - & - & 5 & 11 & 3 \\
\hline 5. & Menu berfungsi dengan baik & - & - & 2 & 12 & 5 \\
\hline 6. & $\begin{array}{l}\text { Informasi wisata dan hotel } \\
\text { sudah lengkap }\end{array}$ & - & - & 4 & 11 & 4 \\
\hline 7. & $\begin{array}{l}\text { Aplikasi bermanfaat bagi } \\
\text { banyak orang }\end{array}$ & - & - & 1 & 9 & 9 \\
\hline Persentase : & $0 \%$ & $0 \%$ & $12.8 \%$ & $58.6 \%$ & $28.5 \%$ \\
\hline
\end{tabular}

\section{KESIMPULAN DAN SARAN}

\subsection{Kesimpulan}

Berdasarkan pengujian dan pembahasan yang telah dilakukan maka dapat ditarik beberapa kesimpulan sebagai berikut.

1. Berdasarkan hasil pengujian fungsional system yang telah dilakukan dapat disimpulkan bahwa aplikasi pencarian hotel terdekat berbasis android Dapat berjalan dengan baik di 4 sistem operasi android yaitu Pie, Oreo, Marshmallow dan KitKat

2. Hasil pengujian pengguna menunjukkan bahwa $0 \%$ pengguna menyatakan sangat tidak setuju, 0\% pengguna menyatakan tidak setuju, $12.8 \%$ menyatakan bahwa pengguna netral, $58.6 \%$ menyatakan bahwa pengguna Setuju dan $28.5 \%$ menyatakan bahwa pengguna sangat setuju.

\subsection{Saran}

Adapun saran yang dapat diberikan setelah melakukan pengujian sebagai berikut.

1. Jumlah tempat wisata,hotel dan restoran bisa ditambah lagi.

2. Untuk kedepannya bisa menambahkan fitur rute alternatif menuju lokasi wisata atau hotel di kabupaten timor tengah utara

\section{DAFTAR PUSTAKA}

[1] Adi Jaya Prasetyo, Pencarian Hotel Terdekat Di Kota Malang Mengunakan Metode Location Based Service, JATI (Jurnal Mahasiswa Teknik Informatika) Vol. 2 No. 1, Maret 2018.

[2] Ali Khaidir, Aplikasi Pencarian Tempat Ibadah Menggunakan Metode Lbs (Location Based Service) Berbasis Android, JATI (Jurnal Mahasiswa Teknik Informatika) Vol. 1 No. 1, Maret 2017

[3] Fitriana Ariyani, Aplikasi Pencarian Lokasi Lembaga Kursus Dan Pelatihan Di Kota Malang Menggunakan Metode Lbs (Location Based Service), JATI (Jurnal Mahasiswa Teknik Informatika) Vol. 2 No. 1, Maret 2018

[4] Hasbullah Salman Alfarisi, Aplikasi Pencari Tempat Pencucian Mobil Dan Motor Di Kota Malang Menggunakan Metode Location Based Service (Lbs) Berbasis Android, JATI (Jurnal Mahasiswa Teknik Informatika) Vol. 1 No. 2, September 2017

[5] Rahman Ariefka, Aplikasi Mad Ento "Madura Explore And Tour" Dengan Penerapan Metode Location Based Service (Lbs) Berbasis Android, JATI (Jurnal Mahasiswa Teknik Informatika) Vol. 2 No. 1, Maret 2018

[6] Budiman Edy, Pemanfaatan Teknologi Location Based Service Dalam Pengembangan Aplikasi Profil Kampus Universitas Mulawarman Berbasis Mobile, Jurnal Ilmiah ILKOM Volume 8 Nomor 3, Desember 2016

[7] Suyanto Asep Herman, Pemrograman Java : Pengenalan Java, www.jurnalkomputer.com, 2015

[8] Standsyah Rahmawati Erma, Intannia Sari Restu, Implementasi Phpmyadmin Pada Rancangan Sistem Pengadministrasian, Jurnal UJMC, Volume 3, Nomor 2, 2018

[9] Juansyah Andi, Pembangunan Aplikasi Child Tracker Berbasis Assisted - Global Positioning System (A-Gps) Dengan Platform Android, Jurnal Ilmiah Komputer dan Informatika (KOMPUTA) Edisi. 1 Volume. 1 Agustus 2015 